\title{
Clinical and neurophysiological studies with the aldose reductase inhibitor, sorbinil, in symptomatic diabetic neuropathy
}

\author{
I. G. Lewin, I. A. D. O'Brien, M. H. Morgan and R. J. M.Corrall \\ Department of Medicine, Bristol Royal Infirmary, Bristol, UK
}

\begin{abstract}
Summary. The effect of sorbinil ( $200 \mathrm{mg}$ daily for 4 weeks) was examined in 13 patients, mean age 59.7 years (range 42-72 years), with symptomatic diabetic neuropathy of mean duration 6 years (range 1-18 years). In this double-blind, placebo-controlled crossover trial, studies were made of motor, sensory and autonomic nerve function, severity of painful symptoms and duration of sleep. One patient was withdrawn because of an adverse reaction to sorbinil. In the other 12, constant mean values for glycosylated haemoglobin $\mathrm{A}_{1}$ between $11 \%$ and $12 \%$ indicated stable though not ideal diabetic control throughout the study. Example values for nerve conduction velocity on placebo and active treatment were: $44.3 \pm 5.9$ and $44.8 \pm 5.1$ metres $/ \mathrm{s}$ (mean \pm SD) for median
\end{abstract}

motor nerve, $38.4 \pm 8.2$ and $37.2 \pm 7.7$ metres $/ \mathrm{s}$ for median sensory nerve. Thus there was no significant effect of sorbinil on conduction velocity in these or any other of the motor and sensory nerves tested. Abnormal autonomic function was not improved by sorbinil. Subjective pain scores on a $10 \mathrm{~cm}$ visual analogue scale were $4.2 \pm 2.4$ on placebo and $4.3 \pm 2.4$ after sorbinil. Duration of sleep on placebo and active treatment was $6.1 \pm 1.6$ and $6.2 \pm 1.7 \mathrm{~h} / \mathrm{night}$, respectively. We were not able to detect any beneficial effect of sorbinil on painful diabetic neuropathy in our patients.

Key words: Aldose reductase inhibitor, sorbinil, diabetic neuropathy.
Peripheral neuropathy is a common complication of diabetes mellitus and in some patients severe pain may be experienced which is refractory to conventional treatments. Impaired nerve function may be related to inadequate control of blood glucose levels $[1,2]$. Recently, improvement in glycaemic control using continuous subcutaneous insulin infusion $[3,4]$ and intensive intermittent subcutaneous insulin injections [5] have been associated with an observed improvements in neurophysiological function. Unfortunately, there are many difficulties in implementing such regimens so that normal or near normal blood glucose levels cannot be achieved in many patients. Effective alternative treatments for symptomatic diabetic neuropathy would therefore be valuable.

Sorbitol and fructose accumulate in the nerves of diabetic animals and man in proportion to the degree of hyperglycaemia $[6,7]$ and have been implicated in the impaired nerve conduction $[8,9]$. Inhibition of aldose reductase, the first and rate-limiting enzyme in the polyol pathway, has a beneficial effect on nerve conduction in rats with spontaneous galactosaemia and with streptozotocin-induced diabetes $[6,10]$. Sorbinil, a non-competitive inhibitor of aldose reductase, has recently be- come available for use in man. Initial reports have suggested that treatment with this inhibitor may improve motor and sensory nerve conduction velocities [11] and reduce painful symptoms and weakness [12] in patients with diabetic neuropathy. In the present study we have examined the effects of this drug in patients with symptomatic diabetic neuropathy.

\section{Subjects and methods}

\section{Subjects and study design}

A randomised double-blind placebo-controlled trial was conducted over a 16-week period. Ethical Committee approval was obtained and all patients gave informed consent. Thirteen patients (eight males, five females) entered the study; all were within $10 \%$ of their ideal body weight. The mean age was 59.7 years (range $42-72$ years), mean duration of diabetes was 17.3 years (range $1-28$ years) and the mean duration of neuropathic symptoms was 6 years (range $0.5-17.5$ years). Five patients also had symptomatic ischaemic heart disease and two had hypertension. Seven patients were receiving insulin, five were on oral hypoglycaemic agents and one was on diet alone.

Diabetic control was optimised before entry into the trial and monitored by measurement of glycosylated haemoglobin concentration [13], the normal range being $5.5 \%$ to $7.5 \%$. Placebo capsules were given to all patients during a run-in period (weeks 1-4) and for the 
washout period (weeks 9-12). Sorbinil (200 mg daily), or placebo in identical capsules, was given in random order during weeks 5-8 or weeks $13-16$. The compliance of patients was confirmed by the counting of returned capsules and in five patients by assay of plasma sorbinil concentrations [14]. Patient assessment at entry into the trial and at 4-weekly intervals included neurological examination, nerve conduction tests on the dominant side and autonomic function tests.

\section{Nerve conduction measurements}

Motor nerve conduction velocity was measured using surface recording electrodes placed $3 \mathrm{~cm}$ apart over the abductor pollicis brevis, abductor digiti minimi, extensor digitorum brevis and abductor hallucis muscles. Bipolar surface electrodes, with $2.5 \mathrm{~cm}$-separation and cathodal electrode distal, were used to stimulate the median nerve at the wrist and elbow, and the ulnar nerve at the wrist, below as well as above the elbow, and in the upper arm. Similar procedures were used for the lateral popliteal nerve at the ankle and the head of the fibula, and the tibial nerve at the ankle and in the popliteal fossa. Supramaximal motor action potentials were recorded; the amplification and time scale were suitably increased to obtain latency measurements from the superimposition of consecutive potentials which were stored on the oscilloscope screen and also plotted on aluminised paper, using a DISA 1500 four channel EMG machine (DISA, Bristol, UK). Latencies were measured to the onset of these potentials using the superimposition method of Halar et al. [15]. Orthodromic sensory conduction velocity was measured from the index finger to the median nerve, and from the fifth finger to the ulnar nerve at the wrist. Square wave pulses of $0.2 \mathrm{~ms}$ duration at $2 \mathrm{~s}$ per second were delivered using ring electrodes $2.5 \mathrm{~cm}$ apart, the cathode being proximal, and $1 \mathrm{~cm}$ distal to the interdigital cleft. Surface recording electrodes $2.5 \mathrm{~cm}$ apart were placed with the cathode nearer the stimulus cathode. Similar procedures were used for the radial nerve at the wrist, stimulating the base of the thumb, and for the sural nerve at the ankle to allow recording in the antidromic direction. Electrodes were placed in the first dorsal interosseous space, and $14 \mathrm{~cm}$ proximal to the ankle for antidromic recording of the radial nerve at the wrist and the sural nerve at the ankle. A stimulus strength of three times sensory threshold was used. Mixed nerve action potentials were obtained using similar electrode placings over the median and ulnar nerves just above the elbow, stimuli being applied to the nerves at the wrist. In all cases an average of 16 or 32 responses was obtained and the latencies measured to the onset of the negative deflection. Limb temperature was maintained at $34^{\circ} \mathrm{C}$ using a DISA infra-red heater with feedback control from a skin temperature thermistor (DISA, Bristol, UK). The coefficients of variation for repeated estimations of each nerve conduction velocity in individual diabetic patients $(n=7)$ were all less than $10 \%$. Vibration perception thresholds were measured at the great toe and the medial malleolus of the dominant limb using a Biothesiometer (Biomedical Instruments, Newbury, Ohio, USA).

\section{Autonomic function tests}

Autonomic function was assessed by tests recommended for the diagnosis of diabetic autonomic neuropathy [16]. Beat to beat variation in heart rate was measured using an instantaneous cardiac ratemeter, Lectromed type 4522 (Lectromed, St.Quen, Jersey), interfaced with a Commodore PET 2008N microcomputer (Commodore Business Machines, Slough, Bucks, UK). This was programmed to give a continuous display of heart rate, maximum and minimum heart rate, and to calculate standard deviation and mean of heart rate for a given period. The maximum/minimum heart rate ratio and the standard deviation of the mean heart rate were each measured during the following four procedures to give eight indices of autonomic function: (1) basal heart rate over $60 \mathrm{~s}$ after 10 min supine rest; (2) deep inspiration and expiration each over $5 \mathrm{~s}$; (3) Valsalva manoeuvre, maintaining an expiratory pressure of $40 \mathrm{mmHg}$ for $15 \mathrm{~s}$, recording for a total of $60 \mathrm{~s}$; (4) rising from supine to standing position, recording over $60 \mathrm{~s}$. In addition, postural change in systolic blood pressure was also determined, supine and $60 \mathrm{~s}$ after standing. Coefficients of variation in individual patients $(n=7)$ for maximum/minimum heart rate ratio were: resting $3 \%$; single deep breath $9 \%$; Valsalva $4 \%$ and standing $2 \%$. Values for $\mathrm{SD}$ of mean heart rate were: resting $38 \%$; single deep breath $46 \%$; Valsalva $32 \%$ and standing $27 \%$.

\section{Pain severity}

Patients were asked to keep a daily record of pain severity using a $10-\mathrm{cm}$ visual analogue scale with a range from zero (no pain) to 10 (very severe pain). They were asked to note analgesic consumption and duration of sleep.

\section{Statistical analysis}

Results are given as mean \pm SD. Statistical analyses were by paired ttest and Wilcoxon matched-pairs signed-ranks test using two-tailed $p$ values.

\section{Results}

One patient developed a febrile illness with rash and oral ulceration 21 days after starting sorbinil; this resolved on withdrawal. Twelve patients therefore completed the study.

Glycosylated haemoglobin $A_{1}$ remained unchanged throughout the study, indicating stable diabetic control. Thus, at entry into the trial the mean value was $11.6 \pm$ $2.4 \%$ and at subsequent 4-weekly intervals it was consecutively $11.0 \pm 3.4 \%, 12.0 \pm 2.5 \%, 11.7 \pm 3.2 \%$ and $11.4 \pm 2.3 \%$. Mean plasma sorbinil concentration, measured at the end of the treatment period in five of the 12 patients, was $10.6 \pm 3.4 \mathrm{mg} / \mathrm{l}$ (range $6.3-14.5 \mathrm{mg} / \mathrm{l}$ ).

Motor nerve conduction velocities are shown in Figure 1; sensory and mixed nerve conduction velocities are shown in Figure 2. Sorbinil treatment resulted in no significant change in motor, sensory or mixed nerve conduction velocities, amplitude of motor or sensory action potentials or distal motor latency.

Vibration perception thresholds were unchanged by treatment with sorbinil. Thus, values for the great toe before and after treatment were respectively $36.8 \pm 12.7$ and $32.7 \pm 15.4$ volts. Equivalent values for the medial malleolus were respectively $30.8 \pm 18.3$ and $33.0 \pm$ 14.3 volts.

Autonomic function tests were evaluated in seven of the 12 patients who completed the trial. The other five were excluded because of therapy with $\beta$-adrenergic antagonists. Only one patient had a normal response to all nine tests of autonomic function before treatment by comparison with age-matched control subjects. There was no significant change in any of the autonomic function tests after sorbinil treatment (Table 1).

The severity of neuropathic symptoms was unaffected by sorbinil treatment. The mean subjective visual analogue rating score for pain was $4.2 \pm 2.4$ during placebo and $4.3 \pm 2.4$ during sorbinil treatment. Analgesic drugs were used in conventional doses by nine of the 12 patients: paracetamol alone in three; aspirin alone in 


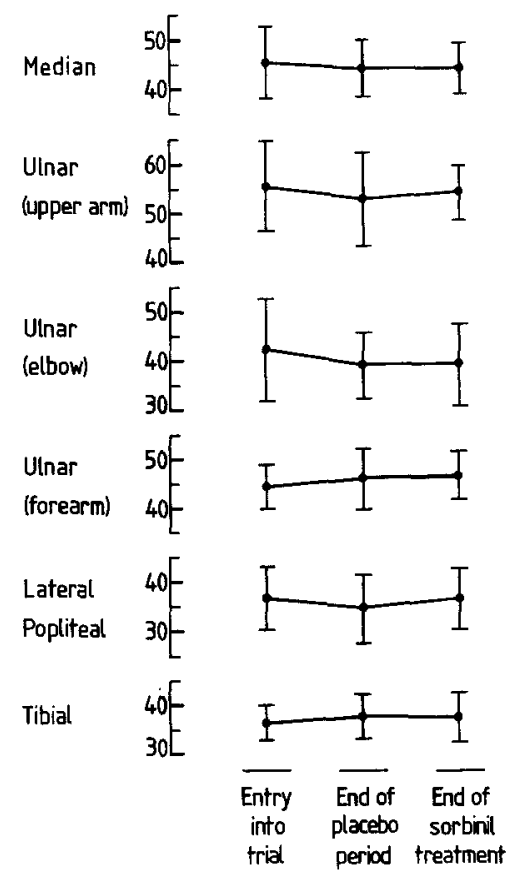

Fig. 1. Motor nerve conduction velocities in metres/s (mean $\pm S D)$ at entry into the trial, at the end of the placebo period and at the end of sorbinil treatment. Lower limits of normal (mean-2SD) in metres/s for each nerve are: median 46.3; ulnar, upper arm 44.1; ulnar, elbow 39.1 ; ulnar, forearm 43.6 ; lateral popliteal 40.1 and tibial 38.7

one; paracetamol plus aspirin in one; paracetamol plus dihydrocodeine in one and paracetamol plus dextropropoxyphene in three. There was no effect of sorbinil on the consumption of these analgesic drugs. The duration of sleep was similar during placebo and sorbinil treatment $(6.1 \pm 1.6$ and $6.2 \pm 1.7 \mathrm{~h}$ per night respective$1 y)$.

\section{Discussion}

Activity of the polyol pathway during hyperglycaemia has been implicated in the pathogenesis of diabetic cataract and polyneuropathy $[8,9]$. In the diabetic rat these complications can be ameliorated by aldose reductase inhibition $[10,17]$, thus demonstrating a reversible component, at least over a relatively short period in this species. In man, elevated sorbitol and fructose concentrations are found in the nerves of diabetic patients [18] and the reduction of erythrocyte sorbitol levels by sorbinil in diabetic patients [19] suggests a possible role for this agent in the treatment of diabetic neuropathy. In normal subjects, sorbinil is eliminated slowly from the circulation with a half-time of disappearance of $34-52 \mathrm{~h}$. Serum levels of the drug plateau within 6-10 days of beginning once-daily oral treatment [14].

In two recent reports in diabetic patients with impaired nerve conduction [11, 12], increases in both mo-

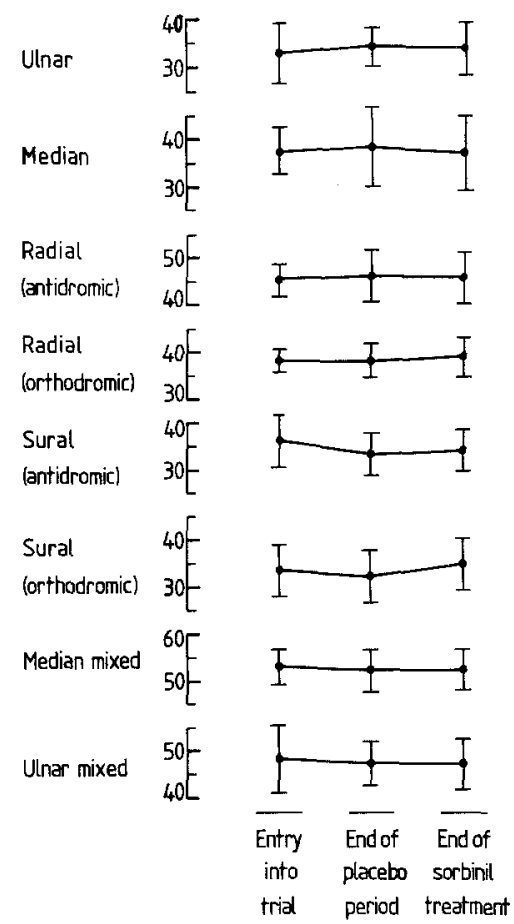

Fig. 2. Sensory and mixed nerve conduction velocities in metres/s (mean $\pm \mathrm{SD}$ ): at entry into the trial, at the end of the placebo period and at the end of sorbinil treatment. Lower limits of normal (mean-2SD) in metres/s for each nerve are: ulnar 40.5; median 41.7; radial, antidromic 46.1 ; radial, orthodromic 46.0 ; sural, antidromic 39.0 ; sural, orthodromic 48.0 ; median mixed 59.0 and ulnar mixed 49.3

Table 1. Results of autonomic function tests in seven patients at the end of the placebo period and after 4 weeks' treatment with sorbinil

\begin{tabular}{lll}
\hline & Placebo & Sorbinil \\
\hline $\begin{array}{l}\text { Maximum/minimum heart rate ratio } \\
\quad \text { Resting }\end{array}$ & $1.06 \pm 0.03$ & $1.06 \pm 0.05$ \\
Inspiration & $1.16 \pm 0.21$ & $1.07 \pm 0.04$ \\
Valsalva & $1.20 \pm 0.15$ & $1.17 \pm 0.11$ \\
$\quad$ Standing & $1.09 \pm 0.07$ & $1.10 \pm 0.09$ \\
SD of mean heart rate & & \\
$\quad$ Resting & $1.07 \pm 0.56$ & $1.17 \pm 0.47$ \\
$\quad$ Inspiration & $3.61 \pm 3.69$ & $1.84 \pm 1.02$ \\
Valsalva & $4.54 \pm 3.15$ & $3.75 \pm 1.65$ \\
$\quad$ Standing & $1.86 \pm 1.10$ & $1.70 \pm 1.20$ \\
Change in systolic blood & $-2 \pm 14$ & $-1 \pm 11$ \\
pressure (mmHg) & & \\
\hline
\end{tabular}

Results expressed as mean $\pm \mathrm{SD}$

tor and sensory nerve conduction velocities were found within several weeks of beginning treatment with sorbinil. One of the studies, using a single-blind protocol, also noted an improvement in painful symptoms, muscle strength and autonomic function [12].

We were not able to demonstrate such beneficial effects in our patients and the reasons for this are not clear. Two of the studies $[11,12]$ used a higher daily dose of sorbinil (250 $\mathrm{mg}$ compared with our regimen of $200 \mathrm{mg}$ ), but plasma sorbinil concentrations in our patients were not unlike those reported by Judzewitsch et 
al. [11] and might have been expected to confer similar benefit. The relatively short duration of treatment in our study might have been insufficient to permit improvement. However, Judzewitsch et al. [11] showed that improvement occurred rapidly, was maximal after only 3 weeks and remained stable for the subsequent 6 weeks of their trial. A rapid response to treatment was also noted by Jaspan et al. [12].

An important difference between our study and those of Judzewitsch et al. [11] and Jaspan et al. [12] lies in the selection of patients. Their patients were younger with mean ages of 48 and 42 years respectively compared with 60 years in ours. The patients studied by Judzewitsch et al. had a shorter mean duration of diabetes than ours (10 years compared with 17 years) and they were clinically less severely affected, all being asymptomatic. The patients of Jaspan et al. had a similar mean duration of diabetes (16 years) to ours and they had refractory painful symptoms, but mean nerve conduction velocities were faster than in our patients. Our patients may therefore have had a smaller reversible component to their neuropathy than those in the other studies. It is also possible that changes in nerve function did occur which were not apparent using our methods in a small number of patients. The discretionary use of analgesic drugs by our patients might have obscured a small effect of sorbinil on painful symptoms. Even so, a clinically useful effect might be expected to produce a downward trend in the number of analgesic tablets consumed, a fall in subjective pain scores and an increase in the duration of sleep. These changes were not observed.

In the present study, we have failed to demonstrate improvement in motor, sensory or autonomic nerve function in patients with symptomatic diabetic neuropathy during sorbinil treatment. A more prolonged trial in younger and less severely affected patients is now in progress; this may help to define more clearly the role of sorbinil in diabetic neuropathy.

\section{References}

1. Graf RJ, Halter JB, Halar E, Porte D Jr (1979) Nerve conduction abnormalities in untreated maturity-onset diabetes: relation to levels of fasting plasma glucose and glycosylated haemoglobin. Ann Int Med 90: 298-303

2. Porte D Jr, Graf RJ, Halter JB, Pfeifer MA, Halar E (1981) Diabetic neuropathy and plasma glucose control. Am J Med 70: 195-200

3. Pietri A, Ehle AL, Raskin P (1980) Changes in nerve conduction velocity after six weeks of glucoregulation with portable infusion pumps. Diabetes 29: 668-671
4. Boulton AJ, Drury J, Clarke B, Ward JD (1982) Continuous subcutaneous insulin infusion in the management of painful diabetic neuropathy. Diabetes Care 5: 386-390

5. Holman RR, Dornan TL, Mayon-White V, Howard-Williams J, Orde-Peckar C, Jenkins L, Steemson J, Rolfe R, Smith B, Barbour D, McPherson K, Poon P, Rizza C, Mann JI, Knight AH, Bron AJ, Turner RC (1983) Prevention of deterioration of renal and sensory-nerve function by more intensive management of insulin-dependent diabetic patients. Lancet 1: 204-208

6. Gabbay KH (1973) Role of sorbitol pathway in neuropathy. Adv Metab Dis 2 (Suppl 2): 417-424

7. Dyck PJ, Sherman WR, Hallcher LM, Service FJ, O'Brien PC, Grina LA, Palumbo PJ, Swanson CJ (1980) Human diabetic endoneurial sorbitol, fructose and myo-inositol related to sural nerve morphometry. Ann Neurol 8: 590-596

8. Clements RS Jr (1979) Diabetic neuropathy. New concepts of its aetiology. Diabetes 28: 604-611

9. Brownlee M, Cerami A (1981) The biochemistry of the complications of diabetes mellitus. Ann Rev Biochem 50:385-432

10. Yue DK, Hanwell MA, Satchell PM, Turtle JR (1982) The effect of aldose reductase inhibition on motor nerve conduction velocity in diabetic rats. Diabetes 31: 789-794

11. Judzewitsch RG, Jaspan JB, Polonsky KS, Weinberg CR, Halter JB, Halar E, Pfeifer MA, Vukadinovic C, Bernstein L, Schneider M, Liang K-Y, Gabbay KH, Rubenstein AH, Porte D Jr (1983) Aldose reductase inhibition improves nerve conduction velocity in diabetic patients. N Engl J Med 308: 119-125

12. Jaspan J, Maselli R, Herold K, Bartkus C (1983) Treatment of severely painful diabetic neuropathy with an aldose reductase inhibitor: relief of pain and improved somatic and autonomic nerve function. Lancet 2: 758-762

13. Menard L, Dempsey ME, Blankstein LA, Aleyassine H, Wacks M, Soeldner JS (1980) Quantitative determination of glycosylated haemoglobin $A_{1}$ by agar gel electrophoresis. Clin Chem 26: 1598-1602

14. Foulds G, O'Brien MM, Bianchine JR, Gabbay KH (1981) Kinetics of an orally absorbed aldose reductase inhibitor, sorbinil. Clin Pharm Ther 30: 693-700

15. Halar EM, Venkatesh ME (1976) Nerve conduction velocity measurements: improved accuracy using superimposed response waves. Arch Phys Med Rehabil 57: 451-457

16. Editorial (1978) Diagnosis of autonomic neuropathy. Br Med J 2: 910-911

17. Kinoshita JH, Fukushi S, Kador P, Merola LO (1979) Aldose reductase in diabetic complications of the eye. Metabolism 28 (Suppl 1): 462-469

18. Mayhew JA, Gillon KRW, Hawthorne JN (1983) Free and lipid inositol, sorbitol and sugars in sciatic nerve obtained post-mortem from diabetic patients and control subjects. Diabetologia 24: 13-15

19. Malone JI, Knox G, Benford S, Tedesco TA (1980) Red cell sorbitol: an indicator of diabetic control. Diabetes 29: 861-864

Received: 5 September 1983

and in revised form: 11 April 1984

Dr. R.J.M. Corrall

Bristol Royal Infirmary

Bristol BS2 8HW

Avon

UK 